\title{
Inherited cobalamin malabsorption. Mutations in three genes reveal functional and ethnic patterns
}

\author{
Stephan M Tanner ${ }^{1 *}$, Amy C Sturm ${ }^{1,2}$, Elizabeth C Baack², Sandya Liyanarachchi ${ }^{1}$ and Albert de la Chapelle
}

\begin{abstract}
Background: Inherited malabsorption of cobalamin (Cbl) causes hematological and neurological abnormalities that can be fatal. Three genes have been implicated in Cbl malabsorption; yet, only about 10\% of 400-500 reported cases have been molecularly studied to date. Recessive mutations in CUBN or AMN cause Imerslund-Gräsbeck Syndrome (IGS), while recessive mutations in GIF cause Intrinsic Factor Deficiency (IFD). IGS and IFD differ in that IGS usually presents with proteinuria, which is not observed in IFD. The genetic heterogeneity and numerous differential diagnoses make clinical assessment difficult.

Methods: We present a large genetic screening study of 154 families or patients with suspected hereditary Cbl malabsorption. Patients and their families have been accrued over a period spanning $>12$ years. Systematic genetic testing of the three genes CUBN, AMN, and GIF was accomplished using a combination of single strand conformation polymorphism and DNA and RNA sequencing. In addition, six genes that were contenders for a role in inherited $\mathrm{Cbl}$ malabsorption were studied in a subset of these patients.
\end{abstract}

Results: Our results revealed population-specific mutations, mutational hotspots, and functionally distinct regions in the three causal genes. We identified mutations in 126/154 unrelated cases (82\%). Fifty-three of 126 cases (42\%) were mutated in CUBN, 45/126 (36\%) were mutated in AMN, and 28/126 (22\%) had mutations in GIF. We found 26 undescribed mutations in CUBN, 19 in $A M N$, and 7 in GIF for a total of 52 novel defects described herein. We excluded six other candidate genes as culprits and concluded that additional genes might be involved.

Conclusions: $\mathrm{Cbl}$ malabsorption is found worldwide and genetically complex. However, our results indicate that population-specific founder mutations are quite common. Consequently, targeted genetic testing has become feasible if ethnic ancestry is considered. These results will facilitate clinical and molecular genetic testing of $\mathrm{Cbl}$ malabsorption. Early diagnosis improves the lifelong care required by these patients and prevents potential neurological long-term complications. This study provides the first comprehensive overview of the genetics that underlies the inherited $\mathrm{Cbl}$ malabsorption phenotype.

Keywords: Vitamin $B_{12}$, Cobalamin, Hereditary cobalamin malabsorption, Amnionless, Gastric intrinsic factor, Cubilin, Ancestry, Genetic testing, Founder mutation, Genetic heterogeneity

\section{Background}

The metabolic pathway of vitamin $\mathrm{B}_{12}$ (Cobalamin, Cbl) was elucidated by studying rare disorders in children $[1,2]$. Deficiency of vitamin $B_{12}$ (Cobalamin, Cbl) in childhood is usually caused by chronic malnutrition, parasitic infections, or genetic defects. With the advent of modern agriculture and medicine, the first two causes have largely disappeared, although they may persist in

\footnotetext{
* Correspondence: smtrmn@gmail.com

${ }^{1}$ Human Cancer Genetics, Comprehensive Cancer Center, The Ohio State University, BRT 850, 460W. 12th Ave, Columbus, OH 43210, USA

Full list of author information is available at the end of the article
}

less developed regions of the world or among individuals who practice unbalanced dietary habits [3]. Genetic defects in Cbl absorption, serum transport, and intracellular metabolism are found worldwide $[1,4,5]$. Clinical symptoms may be present at birth for intracellular defects (complementation groups cblA OMIM251100; cblB OMIM251110; cblC OMIM277400; cblD OMIM277410; cblE OMIM236270; cblF OMIM277380; cblG OMIM 250940) and transcobalamin 2 deficiency (OMIM275350). However, in the case of intestinal Cbl malabsorption, obvious signs emerge usually only after several months or even years, when the fetal supply stored in the liver has

\section{Ciomed Central}


been exhausted [6], and some adolescent cases have been noted $[7,8]$. The signs of $\mathrm{Cbl}$ malabsorption are general weakness, slow growth, developmental delays and learning difficulties, dementia, psychological problems, neurodegeneration of the spinal cord, increased rate of infections due to neutropenia, thrombocytopenia, and megaloblastic anemia with lethal consequences if not treated [9]. Clinical diagnostic markers include low serum $\mathrm{Cbl}$, elevated homocysteine and methylmalonic acid in serum or urine, and exclusion of antibodies against parietal cells and gastric intrinsic factor (IF), whose presence would indicate pernicious anemia. But none of these tests is specific for Cbl malabsorption [10]. The Schilling test [11], measuring the absorption of radio-labeled $\mathrm{Cbl}$, was prematurely retired without an adequate replacement [12]. Ultimately, the final diagnosis is reached by exclusion of many differential diagnoses and can only be confirmed by genetic testing. On the other hand, treatment is often administered via parenteral $\mathrm{Cbl}$ supplementation without confirming the diagnosis [9].

The knowledge of the genetic basis of hereditary $\mathrm{Cbl}$ malabsorption has much improved over the past decade, with three genes now implicated in its etiology. In 1999, the gene CUBN encoding cubilin was found mutated in a series of Finnish patients with selective malabsorption of $\mathrm{Cbl}$ and proteinuria [13], followed by the gene $A M N$ that encodes amnionless, which was found mutated in several Norwegian and Jewish patients $[14,15]$. Recessive mutations in either of these two genes cause the disease known as Imerslund-Gräsbeck syndrome (IGS, megaloblastic anemia 1; OMIM261100) or selective vitamin $B_{12}$ malabsorption with proteinuria [16-19]. Cubilin and amnionless form the cubam dimer, which functions as the ileal receptor for the gastric intrinsic factor and $\mathrm{Cbl}$ complex $\left(\mathrm{IF}-\mathrm{B}_{12}\right)$ that is responsible for uptake of the essential food-born vitamin [20,21]. A clinically similar disease without proteinuria is gastric intrinsic factor deficiency (IFD, OMIM261000 [22]) due to recessive mutations in GIF [23-25]. The two-stage Schilling test [11] distinguishes IGS from IFD by the addition of IF in the second assay step, which corrects the malabsorption of $\mathrm{Cbl}$ in IFD but not in IGS. However, this test is rarely used today [12] and for clinical purposes the differentiation is usually not possible.

With the implication of these three genes, the majority of IGS and IFD can be reliably diagnosed by genetic testing. However, the diagnostic work is daunting given the genetic heterogeneity and therefore many differential diagnoses have to be excluded before one embarks on genetic testing. In addition, the size of $C U B N$, which consists of 67 exons, and $A M N$, which has proved difficult to analyze, complicate the task. Not surprisingly, of about 400-500 patients reported since 1960 , only some
$10 \%$ were genetically tested and many reports include only a few patients $[8,26-36]$. This situation has resulted in an incomplete genetic picture of intestinal $\mathrm{Cbl}$ malabsorption and hampers not only patient care but future research as well.

We present the results of systematic genetic testing in hereditary intestinal Cbl malabsorption among 154 consecutively recruited sibships or patients. We report 52 previously undescribed mutations in $C U B N, A M N$, and GIF and discuss the mutational spectrum in various regions of the world, the genetic testing strategy, functional consequences, and suggest that not all responsible genes have been identified yet.

\section{Subjects and methods \\ Patients}

We studied patients from all over the world. Both parents were available for study in 90 cases, one parent each in 15 cases, and none in 49 cases (Table 1 and Additional file 1). The diagnosis of hereditary deficiency of vitamin $\mathrm{B}_{12}$ absorption was made based on established criteria $[6,16,19]$, usually but not always in tertiary level hospitals. Patients were typically in the range of 6 months to 5 years of age when first diagnosed with $\mathrm{Cbl}$ deficiency, however, several patients were over 5 years old before they displayed chronic health problems. Clinical and laboratory details on work-up, exclusion of differential diagnoses, symptom management, and therapy varied widely according to country and treatment center. Low serum $\mathrm{Cbl}(<200 \mathrm{pg} / \mathrm{ml})$ was the most commonly used marker of $\mathrm{Cbl}$ deficiency, sometimes combined with proteinuria, after exclusion of intestinal parasites and nutritional deficiencies. Only very few cases ever had a Schilling test (Additional file 1).

\section{Patient samples}

Blood samples for DNA or RNA isolation were obtained after informed consent with prior Institutional Review Board approval (OSU protocol 2005 H0201) according to the Declaration of Helsinki. DNA isolation was performed by standard proteinase $\mathrm{K}$ digest, phenolchloroform extraction and $\mathrm{EtOH}$ precipitation at the Ohio State University or locally using commercially available DNA isolation kits from various companies. Total RNA was isolated using the Trizol protocol according to the manufacturer's instructions (Invitrogen, Carlsbad, CA).

\section{Mutation screening and genetic analyses}

We amplified individual exons of CUBN (GenBank RefSeq: NM001081.2), AMN (GenBank RefSeq: NM030943.1), and GIF (GenBank accession NM005142.2) from genomic DNA by PCR and analyzed the PCR amplicons by single strand conformation polymorphism (SSCP, 
Table 1 Genetic study results of 154 patients/families with suspected Cbl malabsorption

\begin{tabular}{|c|c|c|c|c|}
\hline Identifier $^{a}$ & DNA mutation ${ }^{b}$ & Genotype $^{c}$ & $\begin{array}{l}\text { predicted consequence } \\
\text { mRNA or protein level }\end{array}$ & Interpretation \\
\hline$\overline{\mathrm{DT}}$ & CUBN c.250C>T & hom & p.Gln84* & IGS \\
\hline MGA47 & $\begin{array}{l}\text { CUBN c. } 252+1 G>A \text { \& del } \sim 90 \mathrm{~kb} \text { proximal of } \\
5 \text { '-end to Intron } 28\end{array}$ & hom & $\begin{array}{l}\text { splice site mutation \& partial } \\
\text { gene deletion }\end{array}$ & IGS \\
\hline Fam SA & CUBN C.434G $>$ A & hom & p.Gly145Gln & IGS \\
\hline$Z X-1$ & CUBN C.434G>A & hom & p.Gly145Gln & IGS \\
\hline MGA57 & CUBN c.489G >A \& c.1530G>A & comp het & $\begin{array}{l}\text { c.489_490ins137bp; p.Gly164fs } \\
\text { \& Exon } 13 \text { skipping; p.Val473fs }\end{array}$ & IGS \\
\hline Norge 1 & CUBN c.673T>A & hom & p.Cys225Ser & IGS \\
\hline MGA53 & CUBN c.889C>T \& c.1010C>T & comp het & p.GIn297* \& p.Pro337Leu & IGS \\
\hline MGA1 & CUBN c. $1010 C>T \&$ c.2673C $>$ A & comp het & p.Pro337Leu \& p.Cys891* & IGS \\
\hline MGA20 & $\begin{array}{l}\text { CUBN c.1010C>T \& del }>150 \mathrm{~kb} \text { proximal of } \\
5^{\prime} \text {-end to } \sim 150 \mathrm{~kb} \text { distal of } 3 \text { '-end }\end{array}$ & comp het & $\begin{array}{l}\text { p.Pro337Leu \& complete } \\
\text { gene deletion }\end{array}$ & IGS \\
\hline MGA29 & $\begin{array}{l}\text { CUBN c. } 1436 C>\mathrm{G} \& \text { del }>150 \mathrm{~kb} \text { proximal of } \\
\text { 5'-end to }>160 \mathrm{~kb} \text { distal of 3'-end }\end{array}$ & comp het & p.Leu479* \& complete deletion & IGS \\
\hline HS98 & CUBN c.1526delG \& c.1865delC & comp het & p.Gly509fs \& p.Thr621fs & IGS \\
\hline MGA34 & CUBN c.1838delG \& c.3890C>T & comp het & p.Gly613fs \& p.Pro1297Leu & IGS \\
\hline$\overline{\mathrm{KT}}$ & CUBN C.1951C>T & hom & p.Arg651* & IGS \\
\hline Taiwan 1 & CUBN c.1951C>G \& ? & comp het & p.Arg651Gly (rs182512508) \&? & IGS \\
\hline MGA11 & CUBN c.2068A>G \& c.3330-439C>G & comp het & p.lle690Val \& aberrant splicing & IGS \\
\hline MGA66 & CUBN c.2486C >T \& ? & comp het & p.Ser829Leu \& ? & IGS \\
\hline MGA76 & CUBN c.2511_2529del19bp \& c.4168G>A & comp het & p.Pro837fs \& p.Gly1390Ser & IGS \\
\hline MGA3 & CUBN c.2594G>A & hom & p.Ser865Asn & IGS \\
\hline MGA43 & CUBN c.2594G>A \& ? & comp het & p.Ser865Asn \& ? & IGS \\
\hline MT2 & CUBN c.2594G>A \& c.3749C>T & comp het & p.Ser865Asn \& p.Ser1250Phe & IGS \\
\hline $4655-2590$ & CUBN c.2614_2615delGA & hom & p.Asp872fs & IGS \\
\hline MGA78 & CUBN c.2614_2615delGA & hom & p.Asp872fs & IGS \\
\hline MGA56 & CUBN c.2949C>A & hom & p.Tyr983* & IGS \\
\hline MGA14 & CUBN c.3056C>G & hom & p.Ser1019* & IGS \\
\hline MGA26 & CUBN c.3096delT \& ? & comp het & p.Thr1032* \&? & IGS \\
\hline MGA7 & CUBN C.3300-439C>G & hom & aberrant splicing & IGS \\
\hline RL02 & CUBN c.3577T>G & hom & p.Trp1193Gly & IGS \\
\hline FM1(20 cases) & CUBN C.3890C $>T$ & hom & p.Pro1297Leu & IGS \\
\hline AT01 & CUBN C.3890C $>T$ & hom & p.Pro1297Leu & IGS \\
\hline MGA17 & CUBN c.3890C $>T$ & hom & p.Pro1297Leu & IGS \\
\hline MGA72 & CUBN C.3890C $>T$ & hom & p.Pro1297Leu & IGS \\
\hline MGA65 & CUBN c.3999C>A \& ? & comp het & p.Cys1333* \&? & IGS \\
\hline KA95 & CUBN C.4115C>G & hom & p.Thr1372Arg & IGS \\
\hline MGA2 & CUBN C.4115C>G & hom & p.Thr1372Arg & IGS \\
\hline Fam A & AMN c.14delG & hom & p.Gly5fs & IGS \\
\hline Fam C & AMN c.14delG & hom & p.Gly5fs & IGS \\
\hline Fam D & AMN c.14delG & hom & p.Gly5fs & IGS \\
\hline Norge 2 & AMN c.14delG & hom & p.Gly5fs & IGS \\
\hline MGA12 & $A M N$ c. $43+1 G>T \&$ c.701G $>T$ & comp het & $\begin{array}{l}\text { splice site mutation } \\
\& \text { p.Cys } 234 \text { Phe }\end{array}$ & IGS \\
\hline$\overline{M G A 88}$ & AMN c.43+4A>G \& c.100delG & comp het & $\begin{array}{l}\text { splice site mutation } \\
\text { \& p.Ala34fs }\end{array}$ & IGS \\
\hline MGA5 & $A M N$ C. $44-3 C>G$ & hom & splice site mutation & IGS \\
\hline Fam K & $A M N$ c.122C $>T$ & hom & p.Thr41lle & IGS \\
\hline
\end{tabular}


Table 1 Genetic study results of $\mathbf{1 5 4}$ patients/families with suspected Cbl malabsorption (Continued)

\begin{tabular}{|c|c|c|c|c|}
\hline MGA51 & AMN c.122C>T \& C.1118_1119insCGCT & comp het & p.Thr41lle \& p.Leu374fs & IGS \\
\hline MGA77 & AMN c.176T>C & hom & p.Leu59Pro & IGS \\
\hline FT & $A M N$ c.208-1G>C & hom & splice site mutation & IGS \\
\hline Fam M & $A M N$ c.208-2A>G & hom & Exon 4 skipping & IGS \\
\hline$\overline{\mathrm{CT}}$ & $A M N$ c.208-2A>G & hom & Exon 4 skipping & IGS \\
\hline ET & $A M N$ c.208-2A>G & hom & Exon 4 skipping & IGS \\
\hline MT & $A M N$ c.208-2A>G & hom & Exon 4 skipping & IGS \\
\hline Jor 8.7 & $A M N$ c.208-2A>G & hom & Exon 4 skipping & IGS \\
\hline Jor 7.7 & $A M N$ c.208-2A>G & hom & Exon 4 skipping & IGS \\
\hline Fam C89 & $A M N$ c.208-2A>G & hom & Exon 4 skipping & IGS \\
\hline Israel I & $A M N$ c.208-2A>G & hom & Exon 4 skipping & IGS \\
\hline Israel || & $A M N$ c.208-2A>G & hom & Exon 4 skipping & IGS \\
\hline MGA30 & $A M N$ c.208-2A>G & hom & Exon 4 skipping & IGS \\
\hline MGA45 & $A M N$ c.208-2A>G & hom & Exon 4 skipping & IGS \\
\hline MGA52 & $A M N$ c.208-2A>G & hom & Exon 4 skipping & IGS \\
\hline MGA58 & $A M N$ c.208-2A>G & hom & Exon 4 skipping & IGS \\
\hline MGA59 & $A M N$ c.208-2A>G & hom & Exon 4 skipping & IGS \\
\hline MGA69 & $A M N$ c.208-2A>G & hom & Exon 4 skipping & IGS \\
\hline MGA75 & $A M N$ c.208-2A>G & hom & Exon 4 skipping & IGS \\
\hline MGA22 & AMN c.295delG & hom & p.Gly98fs & IGS \\
\hline MGA37 & AMN c.468_469insT \& c.1006+34_48del15bp & comp het & p.Gly157fs \& Exon 9 skipping & IGS \\
\hline$\overline{\mathrm{BT}}$ & $A M N$ c.514-34G $>A$ & hom & $\begin{array}{l}\text { new splice site leading to } \\
\text { c.513_514ins32bp; p.Thr172fs }\end{array}$ & IGS \\
\hline MGA83 & $A M N$ c.663G $>A$ & hom & p.Trp221* & IGS \\
\hline Fam AK & AMN c.683_730del48bp & hom & p.Gln228_Leu243del & IGS \\
\hline$\overline{\mathrm{PT}}$ & $A M N$ c.761G $>A$ & hom & p.Gly254Glu & IGS \\
\hline MGA19 & $\begin{array}{l}\text { AMN c.967_(1169+15)del296bp \& } \\
\text { c.977_978insCCCG }\end{array}$ & comp het & partial gene deletion \& p.Arg326fs & IGS \\
\hline MGA86 & AMN c.1006+16_30del15bp & hom & unknown & IGS \\
\hline Sudan 1 & AMN c.1006+34_48del15bp & hom & Exon 9 skipping & IGS \\
\hline$\overline{M G A 8}$ & AMN c.1006+34_48del15bp & hom & Exon 9 skipping & IGS \\
\hline MGA82 & AMN c.1006+34_48del15bp & hom & Exon 9 skipping & IGS \\
\hline MGA13 & AMN c.1006+34_48del15bp \& c.1314_1315delCA & comp het & Exon 9 skipping \& p.His438fs & IGS \\
\hline Belgium 1 & AMN c.1006+36_50del15bp \& c.1253_1254insA & comp het & unknown \& p.Leu419fs & IGS \\
\hline MGA38 & AMN c.1014_1021delCCTCGGCG & hom & p.Leu339fs & IGS \\
\hline MGA73 & AMN c.1014_1021delCCTCGGCG & hom & p.Leu339fs & IGS \\
\hline MGA81 & AMN c.1170-6C>T \& ? & comp het & splice site mutation? \& ? & IGS? \\
\hline MGA74 & AMN c. $1257+10 C>T$ & hom & splicing defect? & IGS \\
\hline MGA68 & AMN c.1314_1315delCA & hom & p.His438fs & IGS \\
\hline France 1 & GIF c. $79+1 G>A$ & hom & splice site mutation & IFD \\
\hline$\overline{M G A 4}$ & GIF c.79+1G>A & hom & splice site mutation & $\mathrm{IFD}$ \\
\hline MGA25 & GIF c.79+1G>A & hom & splice site mutation & IFD \\
\hline MGA49 & GIF c.79+1G>A \& del Intron 8 to distal of 3'-end & comp het & $\begin{array}{l}\text { splice site mutation \& partial } \\
\text { gene deletion }\end{array}$ & $\mathrm{IFD}$ \\
\hline MGA79 & GIF c.79+1G>A \& c.137C >T & comp het & splice site mutation \& p.Ser46Leu & IFD \\
\hline MGA67 & GIF c.79+1G>A \& c.290T>C & comp het & splice site mutation \& p.Met97Thr & $\mathrm{IFD}$ \\
\hline MGA64 & GIF c.79+1G>A \& c.673A>C & comp het & splice site mutation \& p.Ser225Arg & IFD \\
\hline Kuwait 1 & GIF c.80-1G>A & hom & splice site mutation & IFD \\
\hline Kuwait 2 & GIF c.80-1G>A & hom & splice site mutation & $\mathrm{IFD}$ \\
\hline
\end{tabular}


Table 1 Genetic study results of 154 patients/families with suspected Cbl malabsorption (Continued)

\begin{tabular}{|c|c|c|c|c|}
\hline IT & GIF C.137C>T & hom & p.Ser46Leu & IFD \\
\hline NT & GIF c.137C >T & hom & p.Ser46Leu & IFD \\
\hline$\overline{\mathrm{LT}}$ & GIF c.161delA & hom & p.Asn54fs & IFD \\
\hline Fam 8 & GIF c.183_186delGAAT & hom & p.Met61fs & IFD \\
\hline MGA33 & GIF c.183_186delGAAT & hom & p.Met61fs & IFD \\
\hline MGA55 & GIF c.183_186delGAAT & hom & p.Met61fs & IFD \\
\hline MGA39 & GIF c.183_186delGAAT \& c.659T>C & comp het & p.Met61fs \& p.lle220Thr & IFD \\
\hline MGA27 & GIF c.256+2T>G \& c.659T>C & comp het & splice site mutation \& p.lle220Thr & IFD \\
\hline MGA35 & GIF c.290T>C \& ? & comp het & p.Met97Thr \& ? & IFD \\
\hline MGA54 & GIF c.431_438delAGAAGAAC \& c.974_975insG & comp het & p.Gln144fs \& p.Val325fs & IFD \\
\hline MGA48 & GIF C.469T>C \& ? & comp het? & p.Phe157Leu \& ? & IFD? \\
\hline HT & GIF c.685G>A & hom & p.Ala229Thr & IFD \\
\hline MGA36 & GIF c.685G>A & hom & p.Ala229Thr & IFD \\
\hline D2914 & GIF C.938C >T \& ? & comp het & p.Thr313lle \& ? & IFD \\
\hline MGA24 & GIF c.1073+5G>A & hom & splice site mutation & IFD \\
\hline MGA63 & GIF c.1073+5G>A & hom & splice site mutation & IFD \\
\hline MGA92 & GIF c.1073+5G>A & hom & splice site mutation & IFD \\
\hline AT & GIF c.1175_1176insT & hom & p.Thr393fs & IFD \\
\hline MGA61 & GIF c.1222G>A & hom & p.Glu408Lys & IFD \\
\hline MGA9 & LMBRD1 c.404delC \& c.1056delG & comp het & p.Thr135fs \& p.Leu352fs & cblF defect \\
\hline JCA1 & $\begin{array}{l}\text { AMN/CUBN excluded; } \\
\text { GIF/FUT2/CD320/ABCC1/LMBRD1 screened }\end{array}$ & $\mathrm{n} / \mathrm{a}$ & n/a & differential diagnosis? \\
\hline MGA6 & $\begin{array}{l}\text { AMN/CUBN/GIF/FUT2/CD320/ABCC1/LMBRD1/TCN2 } \\
\text { screened }\end{array}$ & $\mathrm{n} / \mathrm{a}$ & $\mathrm{n} / \mathrm{a}$ & differential diagnosis? \\
\hline MGA10 & AMN/CUBN/GIF/FUT2/CD320/ABCC1/LMBRD1 screened & $\mathrm{n} / \mathrm{a}$ & $\mathrm{n} / \mathrm{a}$ & differential diagnosis? \\
\hline MGA15 & AMN/CUBN/GIF/FUT2/CD320/ABCC1/LMBRD1 screened & $\mathrm{n} / \mathrm{a}$ & $\mathrm{n} / \mathrm{a}$ & differential diagnosis? \\
\hline MGA16 & AMN/CUBN/GIF/FUT2/CD320/ABCC1/LMBRD1 screened & $\mathrm{n} / \mathrm{a}$ & n/a & differential diagnosis? \\
\hline MGA18 & AMN/CUBN/GIF/FUT2/CD320/ABCC1/LMBRD1 screened & $\mathrm{n} / \mathrm{a}$ & $\mathrm{n} / \mathrm{a}$ & differential diagnosis? \\
\hline MGA21 & AMN/CUBN/GIF/FUT2/CD320/ABCC1/LMBRD1 screened & $\mathrm{n} / \mathrm{a}$ & $\mathrm{n} / \mathrm{a}$ & differential diagnosis? \\
\hline MGA23 & $\begin{array}{l}\text { AMN/CUBN/GIF/FUT2/CD320/ABCC1/LMBRD1/TCN2 } \\
\text { screened }\end{array}$ & $\mathrm{n} / \mathrm{a}$ & $\mathrm{n} / \mathrm{a}$ & differential diagnosis? \\
\hline MGA28 & AMN/CUBN/GIF/FUT2/CD320/ABCC1/LMBRD1 screened & $\mathrm{n} / \mathrm{a}$ & $\mathrm{n} / \mathrm{a}$ & differential diagnosis? \\
\hline MGA31 & AMN/CUBN/GIF/FUT2/CD320/ABCC1/LMBRD1 screened & $\mathrm{n} / \mathrm{a}$ & $\mathrm{n} / \mathrm{a}$ & differential diagnosis? \\
\hline MGA32 & AMN/CUBN/GIF/FUT2/CD320/ABCC1/LMBRD1 screened & $\mathrm{n} / \mathrm{a}$ & n/a & differential diagnosis? \\
\hline MGA40 & $\begin{array}{l}\text { AMN/CUBN/GIF excluded; } \\
\text { FUT2/CD320/ABCC1/LMBRD1 screened }\end{array}$ & $\mathrm{n} / \mathrm{a}$ & n/a & differential diagnosis? \\
\hline MGA41 & $\begin{array}{l}\text { AMN/CUBN/GIF excluded; } \\
\text { FUT2/CD320/ABCC1/LMBRD1 screened }\end{array}$ & $\mathrm{n} / \mathrm{a}$ & $\mathrm{n} / \mathrm{a}$ & differential diagnosis? \\
\hline MGA42 & AMN/CUBN/GIF screened & $\mathrm{n} / \mathrm{a}$ & $\mathrm{n} / \mathrm{a}$ & differential diagnosis? \\
\hline MGA44 & AMN/CUBN/GIF/ABCC1/LMBRD1 screened & $\mathrm{n} / \mathrm{a}$ & n/a & differential diagnosis? \\
\hline MGA46 & $\begin{array}{l}\text { CUBN/GIF excluded; } \\
\text { AMN/FUT2/CD320/ABCC1/LMBRD1 screened }\end{array}$ & $\mathrm{n} / \mathrm{a}$ & n/a & differential diagnosis? \\
\hline MGA50 & AMN/CUBN/GIF screened & $\mathrm{n} / \mathrm{a}$ & $\mathrm{n} / \mathrm{a}$ & differential diagnosis? \\
\hline MGA62 & AMN/CUBN/GIF/FUT2/CD320/ABCC1/LMBRD1/TCN1/TCN2 screened & $n / a$ & $\mathrm{n} / \mathrm{a}$ & TCN1 defect? \\
\hline MGA70 & AMN/CUBN/GIF/ABCC1/LMBRD1 screened & $\mathrm{n} / \mathrm{a}$ & $\mathrm{n} / \mathrm{a}$ & differential diagnosis? \\
\hline MGA71 & AMN/CUBN/GIF screened & $\mathrm{n} / \mathrm{a}$ & n/a & differential diagnosis? \\
\hline MGA80 & AMN/CUBN/GIF/ABCC1/LMBRD1 screened & $\mathrm{n} / \mathrm{a}$ & n/a & differential diagnosis? \\
\hline MGA84 & AMN/CUBN/GIF screened & $\mathrm{n} / \mathrm{a}$ & $\mathrm{n} / \mathrm{a}$ & differential diagnosis? \\
\hline MGA85 & AMN excluded; CUBN/GIF screened & $\mathrm{n} / \mathrm{a}$ & $\mathrm{n} / \mathrm{a}$ & differential diagnosis? \\
\hline MGA87 & AMN/CUBN/GIF screened & $\mathrm{n} / \mathrm{a}$ & $\mathrm{n} / \mathrm{a}$ & differential diagnosis? \\
\hline
\end{tabular}


Table 1 Genetic study results of 154 patients/families with suspected Cbl malabsorption (Continued)

\begin{tabular}{lllll}
\hline MGA89 & GIF excluded; AMN/CUBN screened & n/a & n/a & differential diagnosis? \\
\hline MGA90 & AMN/CUBN excluded; GIF screened & n/a & n/a & differential diagnosis? \\
\hline MGA91 & TCN1 c.747+3A>C \& ?; GIF screened & comp het? & splice site mutation? & TCN1 defect?
\end{tabular}

${ }^{a}$ Cases are ordered by the location of the mutations in the three genes CUBN, $A M N$, and GIF, followed by potential differential diagnoses by case code. Additional file 1 online contains a sortable Excel table with additional information.

${ }^{b}$ Numbering relative to adenine in the first ATG start codon of CUBN (GenBank RefSeq: NM001081.2), AMN (GenBank RefSeq: NM030943.1), and GIF (GenBank accession NM005142.2).

chom means homozygous, comp het means compound heterozygous, n/a means not applicable.

${ }^{d}$ Numbering relative to the first methionine deduced from the cDNA sequences. Mutations which seemingly caused a frameshift were described as to where the frameshift occurred rather than when the next stop codon was predicted. Where available experimentally confirmed splicing defects on the mRNA level are listed (for details see text).

[37]) and direct DNA sequencing. Sequencing was performed on an ABI PRISM ${ }^{\circledR} 3730$ DNA analyzer (Applied Biosystems, Foster City, CA). PCR and SSCP conditions and primer sequences are available under a collaborative agreement. All nucleotide numbering is relative to the adenine in the first ATG start codon of the three genes, while the amino acid residue numbering is relative to the first methionine deduced from these cDNA sequences according to standard mutation nomenclature [38]. All exons were sequenced in at least 100 anonymized controls from various ethnic backgrounds (89\% Caucasian, 10\% African-American, 1\% other; [39]. Missense changes were studied for conservation using HomoloGene (Additional file 2) and the PolyPhen-2 program [40]. The genes TCN1, TCN2, FUT2, CD320, LMBRD1, and $A B C C 1$ were screened by DNA sequencing in a selected group of patients (Additional file 1).

\section{Transcript analysis}

Suspected splice site changes were studied by comparing them to consensus sequences in spliceDB [41]. If RNA was available, first-strand cDNA was produced from 0.5$1 \mu \mathrm{g}$ total RNA using the AMV cDNA Synthesis Kit (Roche Applied Science, Indianapolis, IN) according to the instructions with a poly $\mathrm{dT}_{24}$-primer. Subsequent reverse-transcription-PCR was performed with assorted cDNA primers covering the desired regions within CUBN (GenBank RefSeq: NM001081.2), AMN (GenBank RefSeq: NM030943.1), or GIF (GenBank accession NM005142.2). DNA sequencing was performed as above.

\section{Results}

\section{Nature and frequency of the mutations}

We have identified mutations in 126 of 154 (82\%) cases or families that were ostensibly unrelated (Table 1 and Figure 1; Additional files $1 \&$ 2). Of these 126 cases, 53 (42\%) were mutated in CUBN, 45 (36\%) were mutated in $A M N$, and $28(22 \%)$ had mutations in GIF. We analyzed both parents in 75 cases and one parent in eight cases and positive carrier status in all parents was established, excluding any de novo mutations. Parental samples were unavailable for 43 cases. In nine cases only one mutation was identified (see missing mutations). One case (MGA9) was initially classified as IGS, based on a falsepositive Schilling test, but later turned out to be mutated in the gene LMBRD1 coding for a lysosomal $\mathrm{Cbl}$ exporter ( $c b l F$ defect; patient 9 in [42]). Twenty-seven cases (18\%) remain unresolved and sequencing of TCN1, TCN2, FUT2, CD320, LMBRD1, and ABCC1 in selected cases identified no additional mutations (Additional file 1).

Several intronic and suspected silent changes caused splicing defects ( $A M N$ c.514-34G>A and c.1006 +34_48del15bp; CUBN c.489G>A and c.1530G>A) and thus predictions of mRNA processing based on sequence changes might deviate from reality (Table 1 ). Consequently, mutations which seemingly caused a frameshift were described as to where the frameshift occurred rather than when the next stop codon was predicted, unless the consequences on the mRNA level were studied.

\section{Mutations in CUBN}

We have identified 30 CUBN point mutations and three large deletions (Table 1 and Additional file 1) in 53 cases or families. Of these 33 different gene defects, seven were previously reported, while 26 novel changes are presented here.

The most common CUBN mutation was missense change c.3890C $>$ T; p.Pro1297Leu, a Finnish founder mutation in exon $27[13,43]$. It occurred mostly in homozygous state but its relatively high incidence among the Finns ( $>25$ families or cases) also unraveled two other rare CUBN mutations c.1838delG; p.Gly613fs in MGA34 and c.1230+1G>A [15].

Our results showed that several other ethnicityspecific mutations exist in CUBN. Two Saudi Bedouin families shared missense change c.434G $>$ A; p.Gly145Glu (Fam SA in [15] and ZX-1). Missense mutation c.1010C > T; p.Pro337Leu was found three times in combination with other defects in cases of German (MGA53 with p.Gln297* and MGA20 with a large deletion) and Western European origin (case MGA1 with p.Cys891*), suggesting that p.Pro337Leu is a Germanic mutation. Intronic mutation c.3330-439C $>\mathrm{G}$ is Swedish in origin 


\section{Cubilin (3623 aa)}

EGF-like repeats CUB 5-8 proteinuria amnionless-binding IF-Cbl binding mutations

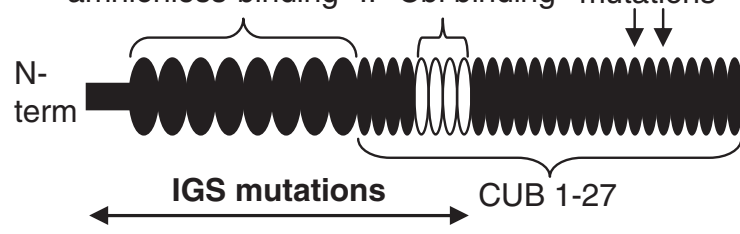

Amnionless (453 aa)

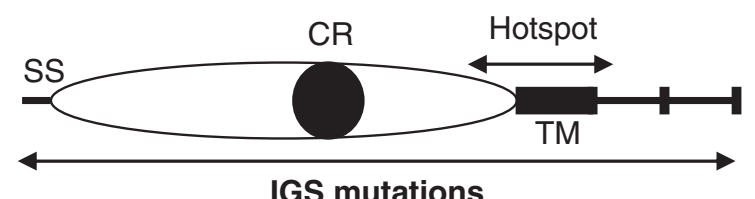

IGS mutations

Intrinsic factor (417 aa)

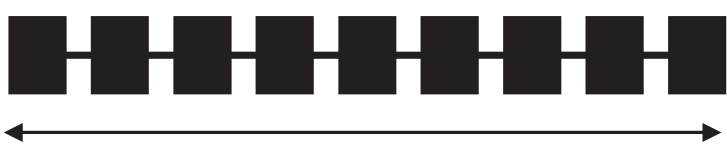

IFD mutations

Figure 1 Illustration of the proteins cubilin and amnionless mutated in IGS and intrinsic factor mutated in IFD, leading to inherited cobalamin malabsorption. Mutations that cause IGS in cubilin were restricted to exons $1-28$ that encode the amnionless binding domain (EGF1-8) and the IF-Cbl binding region (CUB5-8). Two other mutations located towards the carboxy-terminal end ( $p$. Ser2785fs in CUB20 and p.lle2984Val in CUB22) caused proteinuria. Mutations in amnionless and intrinsic factor were located throughout the protein and many mutations affect splicing (Table 1) The mutational hotspot in $A M N$ includes the transmembrane domain and flanking GC-rich repetitive genomic sequences that are apparently unstable (see text). CUB means complement $\mathrm{C} 1 \mathrm{r} / \mathrm{C} 1 \mathrm{~s}$, Uegf, and Bone morphogenic protein-1, EGF means epidermal growth factor repeats, IF means intrinsic factor, CR means cysteine-rich domain, SS means signal sequence (aa 1-19), TM means transmembrane domain (aa 360-380), and aa means amino acid. The proteins are not drawn to scale.

(homozygous in patient MGA7 and case FM2 in [13]; compound in MGA 11 with p.Ile690Val). Furthermore, Ashkenazi frameshift mutation c.2614_2615delGA (cases 4655-2590 and MGA78) and Turkish missense mutation c.4115C >G; p.Thr1372Arg (families KA95 and MGA2) were found twice each homozygously. However, patients from multi-ethnic Turkey carried several different IGS and IFD mutations (Table 1 and Additional file 1).

Missense change c.2594G>A; p.Ser865Asn occurred in Albania (family MGA3, homozygous), Turkey (case MT2 with p.Ser1250Phe), and in a Scottish case in whom the second mutation is still undetected (MGA43). This is the only IGS or IFD mutation we have encountered in one anonymized control individual. However, p.Ser865Asn was heterozygous in that individual, who had no other suspicious changes. Missense change p.Ser865Asn was found at low frequency in the NIH Exome Sequencing Project (rs138083522, A-allele frequency 0.014). Ser865 is not $100 \%$ conserved among mammals and p.Ser865Asn was considered a benign amino acid change (PolyPhen-2 score $=0.007$ ). Thus, its functional relevance is unknown. However, it was seen in four patients, homozygously in two siblings of family MGA3 and once in combination with the damaging mutation p.Ser1250Phe, which suggests that missense p.Ser865Asn is a pathogenic IGS mutation or at least in linkage disequilibrium with an undetected $C U B N$ mutation.

Of the remaining 20 CUBN mutations, 15 are clearly deleterious: two large deletions, seven nonsense, one splice site, and three frameshift mutations. The two alleged silent mutations in individual MGA57 each affected the last nucleotide in exons 5 and 13, respectively. Reverse-transcription-PCR revealed that c.489G >A (exon 5) caused retention of part of intron 5 (137 bp) and c.1530G >A (exon 13) led to the skipping of exon 13 (113 bp), causing a frameshift in both alleles (p.Gly164fs and p.Val473fs).

Of the 5 remaining missense changes, p.Gly1390Ser occurred in combination with a frameshift mutation in family MGA76. Similarly, p.Cys225Ser (patient Norge 1) and p.Trp1193Gly (patient RL02) targeted residues that are $100 \%$ conserved from humans to C. elegans and were considered damaging by PolyPhen-2, supporting their pathogenic role. The other two missense mutations p.Arg651Gly (family Taiwan 1) and p.Ser829Leu (MGA66) are discussed further below.

\section{Mutations in $A M N$}

In total we have detected 27 different $A M N$ mutations of which 19 were previously undescribed (Table 1 and Additional file 1). The most frequent mutation is c.208$2 A>G$, which causes an out-of-frame loss of exon 4 in the mRNA [14]. This ancient founder mutation is about 13,600 years old [44] and causes some $15 \%$ of IGS cases worldwide and more than $50 \%$ among Turks, Jordanians, and Sephardim combined, many of them expatriates. It accounted for 16 of the $45 A M N$-mutated sibships in our cohort. A second acceptor splice site mutation in intron 3 (c.208-1G>C) affected the neighboring nucleotide in family FT.

The second most common mutation is a 15-bp deletion in intron 9 (c.1006+34_48del15bp) that was found in 5 sibships, in two of them combined with other mutations (MGA37: c.468_469insT, and MGA13: c.1314_1315delCA). At first, we assumed that the 15-bp 
deletion was a polymorphism. However, non-Mendelian inheritance patterns of flanking markers indicated that in the presence of this mutation, the wildtype allele in heterozygotes failed to amplify. After designing deletion-specific PCR primers, we were able to show that for example in MGA8 both parents were heterozygous and the patient was homozygous for c.1006 +34_48del15bp. Follow-up reverse-transcription-PCR analysis and DNA sequencing showed that this particular deletion caused the complete loss of exon 9 (163 bp), leading to a frameshift in the resulting mRNA. The mutation occurred in Southwestern Europe (France and Spain) but was also found in Sudan (family Sudan 1) and in the USA (patient MGA82). The differing flanking haplotypes in the European, American, and $\mathrm{Su}-$ danese cases and the fact that two similar 15-bp deletions occurred in patients MGA86 (homozygous c.1006+16_30del15bp) from Yemen and Belgium 1 (compound heterozygous c.1006+36_50del15bp and c.1253_1254insA; [15]) from Europe pointed to a mutational hotspot. Four additional insertion-deletion mutations in the same region accounted for four more cases from Europe (MGA51: c.1118_1119insCGCT with missense c.122C>T; Thr41Ile and MGA19: c.967_(1169 +15)del296bp and c.977_978insCCCG) and Central America (MGA38 and MGA73: homozygous c.1014_1021delCCTCGGCG). Moreover, the heterozygous change c.1170-6C>T in intron 10 (patient MGA81) and a homozygous change (c.1257+10C $>\mathrm{T}$, patient MGA74) in intron 11 might affect mRNA processing as seen with other intronic changes in this region but RNA was not available to study them further. The repetitive and $\mathrm{GC}$-rich region extending from intron 8 to intron 11 ( $838 \mathrm{bp}$ with $75 \% \mathrm{G}+\mathrm{C}$-content) includes the transmembrane domain in exon 10 (aa 360-380; [45]).

The remaining $12 A M N$ mutations were private events in individual families or cases, with the exception of c.1314_1315delCA, which was seen in MGA13 and homozygously in MGA68. Case MGA12 carried a donor splice site and a missense mutation as detailed previously [33]. Patient MGA88 was compound heterozygous for a splice site and a frameshift mutation, while the remaining seven sibships were homozygous for the respective mutation: MGA5, MGA77, MGA22, MGA83, Fam AK [14], PT, and BT with intronic point mutation c.514-34G >A. This ostensibly harmless change activated a cryptic splice site that caused the misincorporation of $32 \mathrm{bp}$ in the mRNA (c.513_514ins32bp; p.Thr172fs).

\section{Mutations in GIF}

In our cohort 28/126 (22\%) carried mutations in GIF. A total of 18 different mutations were identified of which 11 were previously reported and 7 are documented here
(Table 1 and Additional file 1). The most numerous was splice site mutation $\mathrm{c} .79+1 \mathrm{G}>\mathrm{A}$ in intron 1 that was found in seven sibships. Three times it was found homozygously (France 1, MGA4, and MGA25) and four times in combination with other defects: with a 3'-terminal deletion in MGA49 (see below) and with three different missense mutations in MGA79, MGA67, and MGA64, respectively. In patient MGA79 from Siberia it was missense mutation c.137C $>\mathrm{T}$; p.Ser46Leu that was also found in two families from Turkey (IT and NT). Mutation p.Ser46Leu might be a Central Asian founder event but we lack sufficient information to prove that. In patient MGA67, we detected missense change c.290T>C; p.Met97Thr, which was described previously [8] and also occurred in a case from Finland (MGA35). In MGA64, the splice site mutation was compound heterozygous with missense mutation c.673A>C; p.Ser225Arg. Splice site mutation c.79+1G $>\mathrm{A}$ is apparently a Western Caucasian founder mutation, as we have not observed variation on the flanking haplotype.

Two more founder mutations were detected in GIF: c.183_186delGAAT; p.Met61fs, which is African in origin [23] and Chaldean splice site mutation c.1073 $+5 \mathrm{G}>\mathrm{A}$ [46]. While the latter was only found in homozygosity, p.Met61fs once occurred in a mixed AfricanCaucasian patient (MGA39) together with missense mutation c.659T>C; p.Ile220Thr [23]. Residue Ile220 is conserved among mammals and the mutation scored damaging (PolyPhen-2 score 0.998). This missense change was also found in a second case (MGA27) together with a splice site mutation c. $256+2 \mathrm{~T}>\mathrm{G}$ [30].

Kuwaiti acceptor splice site mutation c.80-1G>A and two private insertion-deletion mutations c.161delA (case LT) and c.1175_1176insT (case AT) were described previously [24] and missense change c.1222G>A; p.Glu408Lys in case MGA61 [32] affected a conserved residue. All these mutations were homozygous.

Families HT from Turkey and MGA36 from Lebanon shared the missense mutation c.685G>A; p.Ala229Thr. MGA54 carried two private frameshift mutations: c.431_438delAGAAGAAC and c.974_975insG and may have had a false positive Schilling test. Families MGA48 and D2914 are described below.

\section{Large deletions in CUBN and GIF}

Large gene deletions were discovered via incompatible Mendelian inheritance patterns of sequence polymorphisms or microsatellite markers. All four identified deletions were compound heterozygous with point mutations found on the other allele (Table 1 and Additional file 1). Three large deletions were detected in the CUBN gene, two removed the complete gene (MGA20 and MGA29), while one deletion removed the 5'-half of the gene up to exon 28 (MGA47). In GIF, a partial 
gene deletion extended from intron 8 past the 3 '-end in the two siblings of MGA49. Because of the large physical distances involved we were unable to identify the exact deletion breakpoints via PCR but we have used markers flanking the genes in order to demarcate the deletions.

\section{Missing mutations}

In nine cases, we have found only one likely mutation (one in $A M N$; five in CUBN, and three in GIF; Table 1 and Additional file 1). Four cases had recurrent mutations seen in other IGS or IFD cases or they were clearly deleterious (MGA43, MGA26, MGA65, and MGA35). The remaining five cases (Taiwan 1, MGA66, MGA81, MGA48, and D2914) carried heterozygous changes that were not encountered among controls or dbSNP with the exception of CUBN c.1951C>G; p.Arg651Gly (SNP rs182512508, without frequency information), which was detected in two siblings of family Taiwan 1 . The two affected brothers shared the same CUBN genotype, while residue Arg651 is 100\% conserved among vertebrates and considered detrimental by PolyPhen-2 (score = 1.0). Thus, p.Arg651Gly is likely a pathogenic change. In patient MGA66, the observed missense change CUBN c.2486C $>$ T; p.Ser829Leu likewise affected a highly conserved residue which was considered damaging by PolyPhen-2 (score=1.0). Thus, we concluded that p.Ser829Leu is an IGS mutation.

The change in intron 10 of $A M N$ (c.1170-6C > T) in patient MGA81 was found in the aforementioned unstable GC-rich region of $A M N$. It is therefore possible that this change disturbed the mRNA processing as seen with several other intronic changes in this region but RNA was not available to study it further.

In patient MGA48, only GIF c.469T>C; p.Phe157Leu was detected as a candidate mutation. The IF residue Phe157Leu is conserved among vertebrates with the exception of the dog, which has a leucine residue in place of phenylalanine, thus its exact functional consequences remain to be studied (PolyPhen-2 score $=$ 0.003). However, it was never detected in any other individual or control other than the older sister of the patient, who is healthy and has a different GIF genotype. Thus, p.Phe157Leu is a likely culprit in this Lebanese girl with $\mathrm{Cbl}$ deficiency since the other two genes were excluded. Finally, in patient D2914, missense change GIF c.938C>T; p.Thr313Ile is likely pathogenic (100\% conserved among vertebrates and PolyPhen-2 score $=0.999)$.

\section{Discussion}

\section{Genetic defects in intestinal malabsorption}

The spectrum of mutations in the three genes CUBN, $A M N$, and GIF includes nonsense, missense, insertion- deletion, splice site, and intronic mutations, as well as large deletions first reported herein (Table 1 and Additional file 1).

Given that many mutations appear to be private or restricted to a specific ethnicity or population, estimates of the population frequency of IGS or IFD and their underlying mutations are difficult to make and cannot be extrapolated across populations. Thus, we purposely avoided estimating the frequency of IGS or IFD as we believe it will not be sufficiently accurate to be useful. However, many mutations affect specific ethnic groups; as a result, ancestry was demonstrated to facilitate genetic testing $[23,44,46]$. The genetic heterogeneity led us to develop an ethnicity-focused screening strategy that targets founder mutations first (Figure 2).

\section{CUBN}

Our analyses of 53 families or cases with 33 CUBN mutations show that no IGS mutation was found beyond exon 28 and one of the deletions (case MGA47) covered the same region. This observation is of clinical utility because it suggests that defects beyond exon 28 have no impact on the absorption of $\mathrm{Cbl}$, as long as the protein is stable. In fact, it was shown that a homozygous frameshift mutation in exon 53 of CUBN (c.8355delA; p.Ser2785fs) only caused proteinuria [47]. Moreover, a missense variant in exon 57 (c.8950A > G; p.Ile2984Val) was associated with albuminuria [48]. Thus, mutations in $C U B N$ cause IGS apparently only when they affect the cubilin-amnionless interaction domain (amino-terminal third of cubilin, exons 1-20; [21]) or the IF-Cbl binding site (CUB domains 5-8, exons 21-29; [43]; Figure 1). It is possible that genomic deletions in CUBN are more common and could account for some of the missing mutations and unresolved cases. In individual patients however, deletions can be difficult to detect unless the deletion is homozygous. It is therefore prudent to include parents and siblings in the genetic analysis since the genetic information (heritable SNPs and other variants) might expose genomic deletions. Technically, multiplex ligation-dependent probe amplification (MLPA) or nextgeneration sequencing should detect deletions but an MLPA kit for CUBN is currently not available and whole-genome sequencing for routine diagnostics is still in its infancy.

\section{AMN}

Mutations in $A M N$ are dominated by founder events and a mutational hotspot in the region of introns 8-11 that includes the transmembrane domain in exon 10 [45]. Its analysis was technically challenging because of a highly repetitive GC-content and required high-quality genomic DNA. Moreover, in individuals heterozygous for $A M N$ c.1006+34_48del15bp the wildtype allele 


\section{Genetic diagnostic strategy in intestinal malabsorption of cobalamin}

\begin{tabular}{|c|}
\hline $\begin{array}{c}\text { Exclude nutritional deficiency and } \\
\text { parasites }\end{array}$ \\
\hline$\downarrow$ \\
\hline $\begin{array}{l}\text { Test for proteinuria; presence } \\
\text { supports IGS but absence is not } \\
\text { informative for IFD }\end{array}$ \\
\hline$\downarrow$ \\
\hline $\begin{array}{l}\text { Collect DNA samples from patient, } \\
\text { parents, and siblings (if any) }\end{array}$ \\
\hline \\
\hline Determine ethnicity \\
\hline$\downarrow$ \\
\hline $\begin{array}{l}\text { Priority } 1 \text { search for founder mutations } \\
\text { in that ethnicity }\end{array}$ \\
\hline$\downarrow$ \\
\hline $\begin{array}{l}\text { Priority } 2 \text { search for other known } \\
\text { mutations in that ethnicity }\end{array}$ \\
\hline 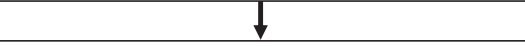 \\
\hline $\begin{array}{l}\text { Priority } 3 \text { screen remaining exons in } \\
G I F \text {, then } A M N \text {, and finally } C U B N\end{array}$ \\
\hline
\end{tabular}

Figure 2 Flow-diagram of the genetic diagnostic strategy in inherited cobalamin malabsorption.

dropped-out during PCR; thus in cases that show seemingly non-Mendelian inheritance of rare changes, a detailed molecular follow-up by RT-PCR or various PCR primer combinations is advisable.

\section{GIF}

A single IFD patient with a homozygous 4-bp deletion in GIF was first described in 2004 [25]. The finding of additional mutations in GIF [24] was the result of a genome-wide search among patients with suspected IGS that were previously excluded for defects in $C U B N$ and $A M N$ [15].

While IF is conserved among Amniota (mammals, birds, and reptiles) the level of conservation among lower vertebrates is less clear. This analysis is complicated by the fact that the genes for transcobalamin 2 (TCN2) and haptocorrin (transcobalamin 1; TCN1) are similar as a result of ancient gene duplication events [1]. The three genes share the same genomic structure with 9 exons and a Cbl binding domain, pointing to a common ancestral gene $[49,50]$. Despite the coding and structural similarities, PCR-based analysis of three genes, GIF, TCN1, and TCN2 has not caused technical problems. Conversely, transcript analysis of GIF using RNA derived from blood cells has proved difficult because the gene is not expressed in that tissue. Even successive rounds of PCR with nested primers and have not succeeded in amplifying the GIF mRNA. This is not particularly surprising since haptocorrin and transcobalamin are the specific Cbl-transporters in the blood [10], and haptocorrin is also found in saliva [51]. Thus, transcript studies of GIF will likely require gastric sampling to obtain the parietal cells that produce IF.

\section{Genotype-phenotype observations}

Because of the limited clinical details that were available from some patients and the fact that many mutations were private, meaningful phenotype-genotype correlations in IGS and IFD were limited. The course of therapy and the health care environment varied widely, as did the age of onset of the symptoms. The most obvious clinical sign, megaloblastic anemia, was not always present and is not unique to IGS or IFD [6]. On the other hand, early hematological and neurological signs can go unnoticed for many months or years. Generally, clinical diagnosis was based on excluding various differential diagnoses, so many patients were only referred for genetic testing several months after acute problems began. However, treatment with parenteral $\mathrm{Cbl}$ was often initiated before a firm diagnosis could be made. Thus, the necessary information to predict the age of onset, the degree of manifestations, and the course of the disease depending on the type of mutation is lacking.

Proteinuria is found in many IGS cases [19] but has rarely been seen in IFD except in two cases from our series, MGA67 and MGA79. We suspect that these two cases had proteinuria unrelated to their IFD defects. The root cause of the proteinuria in IGS is due to the fact that mutations in $C U B N$ or $A M N$ not only prevent the intestinal uptake of $\mathrm{Cbl}$ but may also impair the renal reabsorption of proteins [21,52]. Since amnionless is required to localize cubilin to the luminal membrane in the intestines and kidneys $[34,53]$, deleterious mutations in $A M N$ often cause simultaneous $\mathrm{Cbl}$ deficiency and proteinuria since the cubam complex is no longer able to mediate uptake of its many ligands [52]. In CUBN, mutations in the cubilin-amnionless interaction domain (amino-terminal third of cubilin, exons $\sim 1-20$; [21]) or total loss of the protein may similarly lead to concurrent $\mathrm{Cbl}$ deficiency and proteinuria, while mutations in the IF-Cbl binding site (CUB domains 5-8, exons 21-29; [43]) can cause $\mathrm{Cbl}$ deficiency without proteinuria [19]. The finding of mono-symptomatic proteinuria due to mutations in CUBN (c.8355delA; p.Ser2785fs; [47] and c.8950A $>$ G; p.Ile2984Val; [48]) pointed to the fact that not all mutations in this gene have the same physiological consequences. Thus, defects in cubilin have pleiotropic effects, e.g. for kidney function [54].

Lack of $\mathrm{Cbl}$ not only causes anemia but also impairs neurological function [3]. In young infants, hypotonia, 
seizures, developmental delay, and brain atrophy often occur during the first six months [55]. In severe cases, the patients can perish during early childhood. In older children, movement disorders, dementia, delirium, or psychosis were observed [56]. One IGS case (MGA12) with mutations in $A M N$ showed severe psychosis, which only responded to high-dose Cbl therapy [33]. It was suggested that an active $\mathrm{Cbl}$ transport mechanism at the blood-brain barrier exists, and that amnionless may be part of this mechanism. Consequently, it is possible that certain mutations in CUBN or AMN affect the neurological presentation differently.

Mouse models deficient in CUBN [57] or AMN [45] have been developed and proved embryonic lethal. Given the deleterious nature of many CUBN and $A M N$ mutations in humans, it has become clear that the role of cubilin and amnionless in rodent development is distinct from the role that these proteins play in humans. Thus far, it is not obvious what functions cubilin and amnionless have in primate embryogenesis [58]. IGS was also observed in dogs with two different mutations in the canine $A M N$ gene and the phenotype was similar to that observed in humans [53]. In an attempt to define the differences between rodents and higher mammals regarding $A M N$ [14], we created $A m n$ knock-in mice with three different human IGS mutations (data not shown). The high degree of sequence conservation between human and mouse permitted the identical recreation of the human IGS mutations in the mouse. Two of these mutations (Amn c.14delG; p.Gly5fs and Amn c.683_730del48; p.Gln228_Leu243del) were homozygously lethal, since we never observed any homozygous pups among over 100 offspring in each case (data not shown). On the other hand, the Norwegian missense mutation Amn c. $122 \mathrm{C}>\mathrm{T}$; p.Thr41Ile was viable in the homozygous mouse and without any apparent phenotype (data not shown). Recently, conditional Cubn knock-out mice were created [59], which should permit a better definition of the essential role of cubilin in mouse embryogenesis and renal function.

\section{Other candidate genes}

We have screened 27 cases or sibships (18\%) for mutations in CUBN, $A M N$, and GIF without detecting any pathogenic mutations (Table 1). For seven families the involvement of some or all of the genes was genetically excluded based on different genotypes in two affected siblings (JCA1, MGA40, MGA41, MGA46, MGA85, MGA89, and MGA90). Among the 20 remaining single patients, patients MGA62 and MGA91 were thought to suffer from a defect in the TCN1 gene that encodes haptocorrin. Patient MGA91 carried a novel heterozygous change in intron 5 (TCN1 c. $747+3 \mathrm{~A}>\mathrm{C})$ that was suspect but no RNA was available to study potential splicing aberrations. So far, two truncating mutations have been described in TCN1 [60] but to what degree haptocorrin deficiency plays a role in $\mathrm{Cbl}$ deficiency remains to be studied.

It is conceivable that we have missed some mutations. These could be located in introns or regulatory sequences distant from the exons. However, many cases carried two distinct alleles of the IGS/IFD genes, thus we would have expected two different disease mutations, which would be less likely to be missed. Overall, we have achieved a sensitivity of $82 \%$ in our mutation screening strategy (Figure 2).

Based on their role in transport of $\mathrm{Cbl}$, alternative candidate genes FUT2 [61-63], CD320 [64,65], LMBRD1 [42], and $A B C C 1$ [66] were screened by DNA sequencing in a selected group of unresolved cases but no mutations were found (Additional file 1 and [67]).

Deficiency of transcobalamin 2 (TC2; OMIM275350) with mutations in TCN2 $[68,69]$ represents an alternative diagnosis. Symptoms include megaloblastic anemia, diarrhea, vomiting, failure to thrive, recurring infections, and mental retardation. Thus, many clinical features overlap with IGS and IFD, although mental retardation is not usually associated with IGS and IFD. We sequenced a few atypical cases for mutations in TCN2 (MGA6, MGA23, and MGA62) but found no mutation. In general, TC2 deficiency manifests rapidly in the first 1-2 months after birth and was excluded in most cases before referral for IGS/IFD mutation screening.

Accordingly, $\mathrm{Cbl}$ pathway genes yet to be identified might explain some of these remaining cases of inherited $\mathrm{Cbl}$ deficiency. Based on the documented Cbl uptake pathway (Figure 3), a likely location for failure could be the loading of $\mathrm{TC} 2$ with $\mathrm{Cbl}$ in the enterocyte to form holo-TC2 or the export of holo-TC2 from of the enterocyte. This particular part of the $\mathrm{Cbl}$ transport is not well understood but similarities to the intracellular cblF defect (OMIM277380) that affects the lysosomal membrane transport [70] could be postulated.

\section{Prospective screening recommendations and future prospects}

With the gathered information on ethnicity-specific mutations, it has become feasible to perform targeted screening for common or local founder mutations (Figure 2 and Additional file 1). However, human migrations change the genetic make-up of populations and it is important to trace ethnic ancestry cautiously.

The observation that mutations in CUBN are limited to the first 28 exons has simplified the genetic analysis (Figure 1) but the need to screen three genes remains unchallenged for now because clinical tests cannot 
reliably distinguish IGS and IFD. Parallel, whole-exome or whole-genome sequencing using next generation technology might permit concurrent screening of the three genes. However, clinical laboratory regulations and ethical concerns about the additional sequence data produced will delay the routine introduction of the technology. Consequently, Sanger-based exon-by-exon sequencing will remain the method of choice for the coming years to confirm IGS and IFD.

For clinical diagnostics, a new non-radioactive $\mathrm{Cbl}$ absorption test may eventually replace the Schilling test [71]. The patient is given a dose of cyano-Cbl, which enters the blood unchanged via the intestine in healthy people but not in cases with IGS or IFD. Then the fraction of transcobalamin-bound cyano-Cbl is measured, which reflects the degree of $\mathrm{Cbl}$ absorption. In IGS or IFD, the rate of cyano-Cbl loading of the holo-transcobalamin will be lower. As with the Schilling test, it is conceivable that the addition of IF in a second test step could distinguish IGS from IFD, as the added IF should restore the Cbl absorption in IFD only. This test promises to be more specific than serum levels of total $\mathrm{Cbl}$, methylmalonic acid, or homocysteine [10]. However, questions of sensitivity

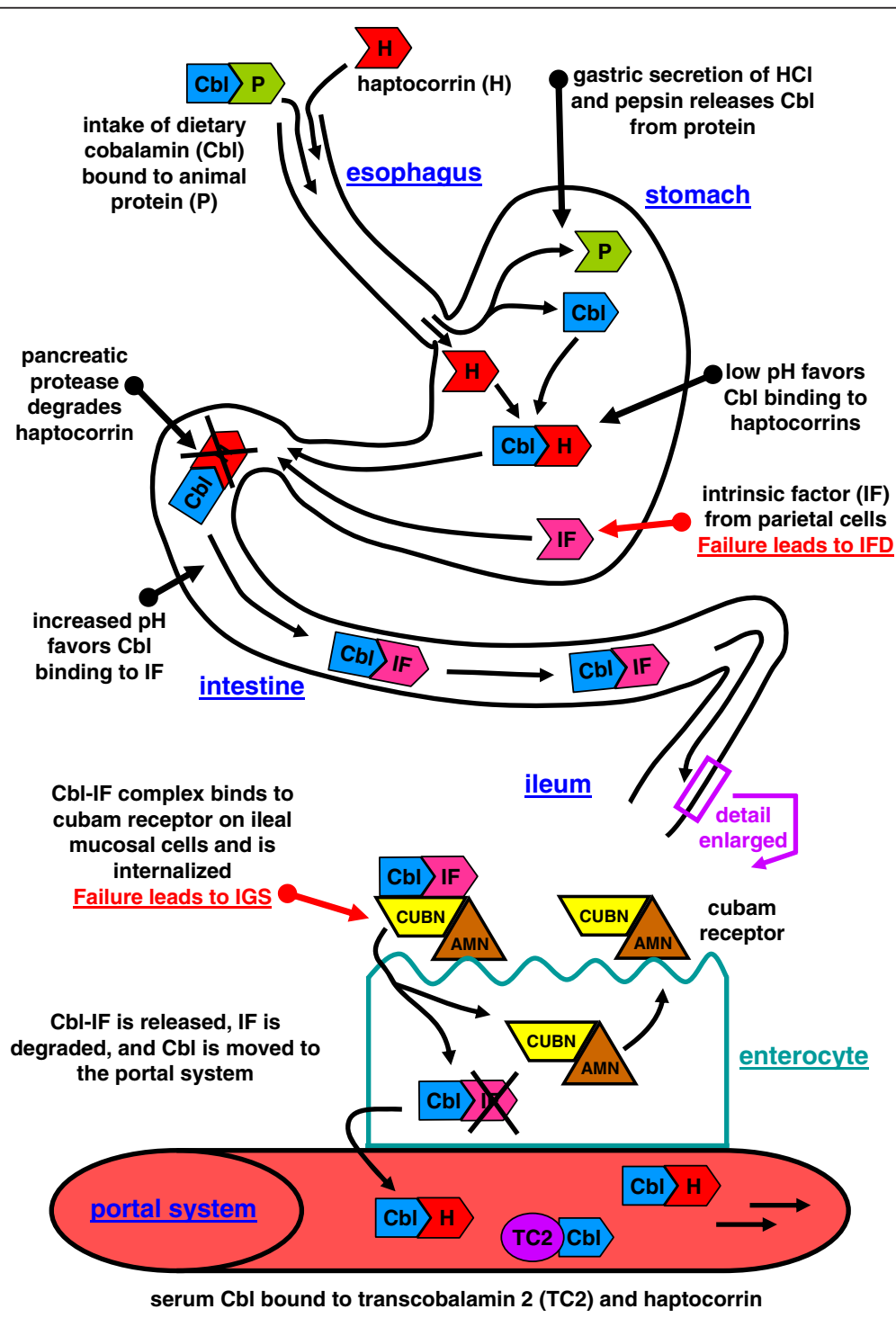

Figure 3 Release of cobalamin from the food and intestinal uptake. Cobalamin (Cbl) uptake and transport pathway from food intake to the portal system. Cbl is released from food proteins (P) by salivary and gastric enzymes and then binds to haptocorrin $(H)$. In the proximal intestine, pancreatic enzymes degrade haptocorrin and Cbl binds to intrinsic factor (IF). In the ileum, the Cbl-IF complex binds to the cubam receptor (CUBN-AMN) and enters the enterocyte (ileal epithelia). Inside the cell, IF is degraded and Cbl is moved to the portal system by an unknown process. The cubam receptor is recycled back to the membrane. In the blood, transcobalamin 2 (TC2) transports Cbl to the tissues. The role of haptocorrin carrying $80 \%$ of the $\mathrm{Cbl}$ serum fraction is unknown. 
remain to be answered but such a test would streamline clinical diagnostics.

\section{Conclusions}

Elucidating the genetic basis of inherited Cbl malabsorption has provided the tools to verify the diagnosis in over $80 \%$ of the cases on the molecular level. In addition, studying this rare phenotype has elucidated the mechanisms and pathway of Cbl uptake in great detail. Our study triples the number of $\mathrm{Cbl}$ malabsorption cases molecularly analyzed and provides a comprehensive overview of the genetic patterns that cause this genetically heterogenous disease. The mutational patterns we have identified should simplify genetic diagnostics.

\section{Additional files}

Additional file 1: Title: Description of all patients and families included in the study. Description: Details and results of all patients and families included in the study.

Additional file 2: Title: Sequence alignments of CUBN, $A M N$, and

GIF. Description: Alignments of the three gene sequences using

HomoloGene with missense mutations highlighted in red.

\section{Competing interests}

The authors have no competing financial interests.

\section{Authors' contributions}

SMT conceived and designed the study, coordinated the research, and wrote the manuscript. ACS and ECB coordinated DNA sample collection and performed genetic counseling. SL helped to draft the manuscript. AdIC commented on the manuscript draft. All authors read and approved the final manuscript.

\section{Acknowledgements}

We thank the families and their clinicians and genetic counselors for supporting our research over many years (Additional file 1). We are grateful to Ralph Gräsbeck, John C. Fyfe, David S. Rosenblatt, Harald Broch, Søren K. Moestrup, and Ralph Green for their advice. We thank Ryan Bisson, Zhongyuan Li, James D. Perko, Cameron M. Beech, Andrea E. Ament, Ceren Acar, Nidhi P. Shah, Ann-Kathrin Eisfeld, and particularly Jan C. Lockman for assistance in the laboratory. This work was supported by grant CA16058 from the National Cancer Institute, USA.

\section{Author details}

${ }^{1}$ Human Cancer Genetics, Comprehensive Cancer Center, The Ohio State University, BRT 850, 460W. 12th Ave, Columbus, OH 43210, USA. ${ }^{2}$ Human Genetics, Department of Internal Medicine, The Ohio State University, Columbus, $\mathrm{OH}$ 43210, USA.

Received: 3 July 2012 Accepted: 23 August 2012

Published: 28 August 2012

\section{References}

1. Watkins D, Rosenblatt DS: Inborn errors of cobalamin absorption and metabolism. Am J Med Genet C Semin Med Genet 2011, 157:33-44.

2. Watkins D, Rosenblatt DS: Update and new concepts in vitamin responsive disorders of folate transport and metabolism. J Inherit Metab Dis 2011, 35:665-670.

3. Allen LH: How common is vitamin B-12 deficiency? Am J Clin Nutr 2009, 89:693S-696S

4. Shinawi M: Hyperhomocysteinemia and cobalamin disorders. Mol Genet Metab 2007, 90:113-121.
5. Whitehead VM: Acquired and inherited disorders of cobalamin and folate in children. Br J Haematol 2006, 134:125-136.

6. Gräsbeck R: Imerslund-Gräsbeck Syndrome (selective vitamin B12 malabsorption with proteinuria). Orphanet journal of rare diseases 2006, $1: 1-17$.

7. Rössler J, Breitenstein S, Havers W: Late onset of Imerslund-Gräsbeck syndrome without proteinuria in four children of one family from the Lebanon. Eur J Pediatr 2003, 162:808-809.

8. Overgaard UM, Tanner SM, Birgens HS: Vitamin B12 deficiency in a 15-year old boy due to mutations in the intrinsic factor gene, GIF. Br J Haematol 2010, 150:369-371.

9. Gräsbeck R, Tanner SM: Juvenile selective vitamin B malabsorption: 50 years after its description-10 years of genetic testing. Pediatr Res 2011, 70:222-228.

10. Carmel R, Green R, Rosenblatt DS, Watkins D: Update on cobalamin, folate, and homocysteine. Hematology (Am Soc Hematol Educ Program) 2003, 62-81.

11. Schilling RF: Intrinsic factor studies II. The effect of gastric juice on the urinary excretion of radioactivity after oral administration of radioactive vitamin B12. J Lab Clin Med 1953, 42:860-866.

12. Carmel R: The disappearance of cobalamin absorption testing: a critical diagnostic loss. J Nutr 2007, 137:2481-2484.

13. Aminoff $M$, Carter JE, Chadwick RB, Johnson C, Gräsbeck R, Abdelaal MA Broch $H$, Jenner LB, Verroust PJ, Moestrup SK, et al: Mutations in CUBN, encoding the intrinsic factor-vitamin B12 receptor, cubilin, cause hereditary megaloblastic anaemia 1. Nat Genet 1999, 21:309-313.

14. Tanner SM, Aminoff M, Wright FA, Liyanarachchi S, Kuronen M, Saarinen A, Massika O, Mandel H, Broch $\mathrm{H}$, de la Chapelle A: Amnionless, essential for mouse gastrulation, is mutated in recessive hereditary megaloblastic anemia. Nat Genet 2003, 33:426-429.

15. Tanner SM, Li Z, Bisson R, Acar C, Oner C, Oner R, Cetin M, Abdelaal MA, Ismail EA, Lissens W, et al: Genetically heterogeneous selective intestinal malabsorption of vitamin B12: founder effects, consanguinity, and high clinical awareness explain aggregations in Scandinavia and the Middle East. Hum Mutat 2004, 23:327-333.

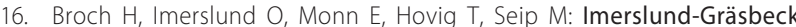
anemia. A long-term follow-up study. Acta Paediatr Scand 1984, 73:248-253.

17. Gräsbeck R, Gordin R, Kantero I, Kuhlbäck B: Selective vitamin B12 malabsorption and proteinuria in young people. Acta Med Scand 1960, 167:289-296.

18. Imerslund O: Idiopathic chronic megaloblastic anemia in children. Acta Paediatr Scand 1960, 1-115.

19. Wahlstedt-Fröberg $V$, Pettersson $T$, Aminoff $M$, Dugué $B$, Gräsbeck R: Proteinuria in cubilin-deficient patients with selective vitamin $B(12)$ malabsorption. Pediatr Nephrol 2003, 18:417-421.

20. Birn H: The kidney in vitamin B12 and folate homeostasis: characterization of receptors for tubular uptake of vitamins and carrier proteins. Am J Physiol Renal Physiol 2006, 291:F22-F36.

21. Fyfe JC, Madsen M, Hojrup P, Christensen El, Tanner SM, de la Chapelle A, He Q, Moestrup SK: The functional cobalamin (vitamin B12)-intrinsic factor receptor is a novel complex of cubilin and amnionless. Blood 2004, 103:1573-1579.

22. Katz M, Lee SK, Cooper BA: Vitamin B 12 malabsorption due to a biologically inert intrinsic factor. N Engl J Med 1972, 287:425-429.

23. Ament AE, Li Z, Sturm AC, Perko JD, Lawson S, Masterson M, Quadros EV, Tanner SM: Juvenile cobalamin deficiency in individuals of African ancestry is caused by a founder mutation in the intrinsic factor gene GIF. Br J Haematol 2009, 144:622-624.

24. Tanner SM, Li Z, Perko JD, Oner C, Cetin M, Altay C, Yurtsever Z, David KL, Faivre L, Ismail EA, et al: Hereditary juvenile cobalamin deficiency caused by mutations in the intrinsic factor gene. Proc Natl Acad Sci U S A 2005, 102:4130-4133.

25. Yassin F, Rothenberg SP, Rao S, Gordon MM, Alpers DH, Quadros EV: Identification of a 4-base deletion in the gene in inherited intrinsic factor deficiency. Blood 2004, 103:1515-1517.

26. Al-Alami JR, Tanner SM, Tayeh MK, de la Chapelle A, El-Shanti H: Homozygous AMN mutation in hereditary selective intestinal malabsorption of vitamin B12 in Jordan. Saudi Med J 2005, 26:1061-1064.

27. Bouchlaka C, Maktouf C, Mahjoub B, Ayadi A, Sfar MT, Sioud M, Gueddich N, Belhadjali Z, Rebai A, Abdelhak S, Dellagi K: Genetic heterogeneity of 
megaloblastic anaemia type 1 in Tunisian patients. J Hum Genet 2007, 52:262-270.

28. Broides A, Yerushalmi B, Levy R, Hadad N, Kaplun N, Tanner SM, de la Chapelle A, Levy J: Imerslund-Grasbeck syndrome associated with recurrent aphthous stomatitis and defective neutrophil function. J Pediatr Hematol Oncol 2006, 28:715-719.

29. Densupsoontorn N, Sanpakit K, Vijarnsorn C, Pattaragarn A, Kangwanpornsiri C, Jatutipsompol C, Tirapongporn H, Jirapinyo P, Shah NP, Sturm AC, Tanner SM: Imerslund-Grasbeck syndrome: New mutation in amnionless. Pediatrics international: official journal of the Japan Pediatric Society 2012, 54:e19-e21.

30. Garcia Jimenez MC, Baldellou Vazquez A, Calvo Martin MT, Perez-Lungmus G, Lopez Pison J: Hereditary juvenile cobalamin deficiency due to mutations in GIF gene. An Pediatr (Barc) 2008, 69:56-58.

31. Hauck FH, Tanner SM, Henker J, Laass MW: Imerslund-Grasbeck syndrome in a 15-year-old German girl caused by compound heterozygous mutations in CUBN. Eur J Pediatr 2008, 167:671-675.

32. Leunbach $T L$, Johansen $P$, Tanner SM, Grasbeck R, Helgestad J: Homozygous mutation in the intrinsic factor gene in a child with severe vitamin B12 deficiency. Ugeskrift for laeger 2011, 173:2047-2048.

33. Luder AS, Tanner SM, de la Chapelle A, Walter JH: Amnionless (AMN) mutations in Imerslund-Gräsbeck syndrome may be associated with disturbed vitamin B(12) transport into the CNS. J Inherit Metab Dis 2008.

34. Namour F, Dobrovoljski G, Chery C, Audonnet S, Feillet F, Sperl W, Gueant $J$ : Luminal expression of cubilin is impaired in Imerslund-Grasbeck syndrome with compound AMN mutations in intron 3 and exon 7. Haematologica 2011, 96:1715-1719.

35. Siddiqui AH, Ansari A, Beech CM, Shah NP, Tanner SM, Sarnaik SA: Juvenile cobalamin deficiency in a 17-year-old child with autonomic dysfunction and skin changes. J Pediatr Hematol Oncol 2012, 34:140-142.

36. Storm T, Emma F, Verroust PJ, Hertz JM, Nielsen R, Christensen El: A patient with cubilin deficiency. N Engl J Med 2011, 364:89-91.

37. Liechti-Gallati S, Schneider V, Neeser D, Kraemer R: Two buffer PAGE system-based SSCP/HD analysis: a general protocol for rapid and sensitive mutation screening in cystic fibrosis and any other human genetic disease. Eur J Hum Genet 1999, 7:590-598.

38. den Dunnen JT, Antonarakis SE: Nomenclature for the description of human sequence variations. Hum Genet 2001, 109:121-124.

39. Tomsic J, Guda K, Liyanarachchi S, Hampel H, Natale L, Markowitz SD, Tanner SM, de la Chapelle A: Allele-specific expression of TGFBR1 in colon cancer patients. Carcinogenesis 2010, 31:1800-1804.

40. Adzhubei IA, Schmidt S, Peshkin L, Ramensky VE, Gerasimova A, Bork P, Kondrashov AS, Sunyaev SR: A method and server for predicting damaging missense mutations. Nat Methods 2010, 7:248-249.

41. Burset M, Seledtsov IA, Solovyev W: SpliceDB: database of canonical and non-canonical mammalian splice sites. Nucleic Acids Res 2001, 29:255-259.

42. Rutsch F, Gailus S, Miousse IR, Suormala T, Sagne C, Toliat MR, Nurnberg G, Wittkampf T, Buers I, Sharifi A, et al: Identification of a putative lysosomal cobalamin exporter altered in the cblF defect of vitamin B12 metabolism. Nat Genet 2009, 41:234-239.

43. Kristiansen M, Kozyraki $R_{\text {, Jacobsen }} C_{1}$ Nexø E, Verroust PJ, Moestrup SK: Molecular dissection of the intrinsic factor-vitamin B12 receptor, cubilin, discloses regions important for membrane association and ligand binding. J Biol Chem 1999, 274:20540-20544.

44. Beech CM, Liyanarachchi S, Shah NP, Sturm AC, Sadiq MF, de la Chapelle A, Tanner SM: Ancient founder mutation is responsible for ImerslundGrasbeck Syndrome among diverse ethnicities. Orphanet journal of rare diseases 2011, 6:74

45. Kalantry S, Manning S, Haub O, Tomihara-Newberger C, Lee HG, Fangman J, Disteche CM, Manova K, Lacy E: The amnionless gene, essential for mouse gastrulation, encodes a visceral-endoderm-specific protein with an extracellular cysteine-rich domain. Nat Genet 2001, 27:412-416.

46. Sturm AC, Baack EC, Armstrong MB, Schiff D, Zia A, Savasan S, de la Chapelle A, Tanner SM: Hereditary Intrinsic Factor Deficiency in Chaldeans. J Inherit Metab Dis 2012, in press.

47. Ovunc B, Otto EA, Vega-Warner V, Saisawat P, Ashraf S, Ramaswami G, Fathy HM, Schoeb D, Chernin G, Lyons RH, et al: Exome sequencing reveals cubilin mutation as a single-gene cause of proteinuria. Journal of the American Society of Nephrology: JASN 2011, 22:1815-1820.

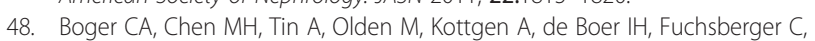
O'Seaghdha CM, Pattaro C, Teumer A, et al: CUBN is a gene locus for albuminuria. Journal of the American Society of Nephrology: JASN 2011, 22:555-570.

49. Greibe E, Fedosov S, Nexo E: The Cobalamin-Binding Protein in Zebrafish Is an Intermediate between the Three Cobalamin-Binding Proteins in Human. PLoS One 2012, 7:e35660

50. Johnston J, Yang-Feng T, Berliner N: Genomic structure and mapping of the chromosomal gene for transcobalamin I (TCN1): comparison to human intrinsic factor. Genomics 1992, 12:459-464.

51. Carmel R: Mild transcobalamin I (haptocorrin) deficiency and low serum cobalamin concentrations. Clin Chem 2003, 49:1367-1374.

52. Nielsen R, Christensen El: Proteinuria and events beyond the slit. Pediatr Nephrol 2010, 25:813-822.

53. He Q, Madsen M, Kilkenney A, Gregory B, Christensen El, Vorum H, Hojrup P, Schaffer AA, Kirkness EF, Tanner SM, et al: Amnionless function is required for cubilin brush-border expression and intrinsic factor-cobalamin (vitamin B12) absorption in vivo. Blood 2005, 106:1447-1453.

54. Reznichenko A, Snieder H, van den Born J, de Borst MH, Damman J, van Dijk MC, van Goor H, Hepkema BG, Hillebrands JL, Leuvenink HG, et al: CUBN as a Novel Locus for End-Stage Renal Disease: Insights from Renal Transplantation. PLoS One 2012, 7:e36512.

55. Lovblad K, Ramelli G, Remonda L, Nirkko AC, Ozdoba C, Schroth G: Retardation of myelination due to dietary vitamin B12 deficiency: cranial MRI findings. Pediatr Radiol 1997, 27:155-158.

56. Bjorke-Monsen AL, Ueland PM: Cobalamin status in children. J Inherit Metab Dis 2011, 34:111-119.

57. Smith BT, Mussell JC, Fleming PA, Barth JL, Spyropoulos DD, Cooley MA, Drake CJ, Argraves WS: Targeted disruption of cubilin reveals essential developmental roles in the structure and function of endoderm and in somite formation. BMC Dev Biol 2006, 6:30.

58. Strope S, Rivi R, Metzger T, Manova K, Lacy E: Mouse amnionless, which is required for primitive streak assembly, mediates cell-surface localization and endocytic function of cubilin on visceral endoderm and kidney proximal tubules. Development 2004, 131:4787-4795.

59. Weyer K, Storm T, Shan J, Vainio S, Kozyraki R, Verroust PJ, Christensen El, Nielsen R: Mouse model of proximal tubule endocytic dysfunction. Nephrol Dial Transplant 2011, 26:3446-3451.

60. Carmel R, Parker J, Kelman Z: Genomic mutations associated with mild and severe deficiencies of transcobalamin I (haptocorrin) that cause mildly and severely low serum cobalamin levels. Br J Haematol 2009, 147:386-391.

61. Hazra A, Kraft P, Lazarus R, Chen C, Chanock SJ, Jacques P, Selhub J, Hunter DJ: Genome-wide significant predictors of metabolites in the one-carbon metabolism pathway. Hum Mol Genet 2009, 18:4677-4687.

62. Hazra A, Kraft P, Selhub J, Giovannucci EL, Thomas G, Hoover RN, Chanock SJ, Hunter DJ: Common variants of FUT2 are associated with plasma vitamin B12 levels. Nat Genet 2008, 40:1160-1162.

63. Tanaka T, Scheet P, Giusti B, Bandinelli S, Piras MG, Usala G, Lai S, Mulas A, Corsi AM, Vestrini A, et al: Genome-wide association study of vitamin B6, vitamin B12, folate, and homocysteine blood concentrations. Am J Hum Genet 2009, 84:477-482.

64. Quadros EV, Lai SC, Nakayama Y, Sequeira JM, Hannibal L, Wang S, Jacobsen DW, Fedosov S, Wright E, Gallagher RC, et al: Positive newborn screen for methylmalonic aciduria identifies the first mutation in TCbIR/CD320, the gene for cellular uptake of transcobalamin-bound vitamin $B(12)$. Hum Mutat 2010, 31:924-929.

65. Quadros EV, Nakayama Y, Sequeira JM: The protein and the gene encoding the receptor for the cellular uptake of transcobalamin-bound cobalamin. Blood 2009, 113:186-192.

66. Beedholm-Ebsen $R$, van de Wetering $K$, Hardlei T, Nexo E, Borst P, Moestrup SK: Identification of multidrug resistance protein 1 (MRP1/ABCC1) as a molecular gate for cellular export of cobalamin. Blood 2010, 115:1632-1639.

67. Shah NP, Beech CM, Sturm AC, Tanner SM: Investigation of the ABC transporter MRP1 in selected patients with presumed defects in vitamin B12 absorption. Blood 2011, 117:4397-4398.

68. Frater-Schroder M: Genetic patterns of transcobalamin II and the relationships with congenital defects. Mol Cell Biochem 1983, 56:5-31.

69. Haberle J, Pauli S, Berning C, Koch HG, Linnebank M: TC II deficiency: avoidance of false-negative molecular genetics by RNA-based investigations. J Hum Genet 2009, 54:331-334 
70. Rutsch F, Gailus S, Suormala T, Fowler B: LMBRD1: the gene for the cbIF defect of vitamin B metabolism. J Inherit Metab Dis 2011, 34:121-126.

71. Hardlei TF, Morkbak AL, Bor MV, Bailey LB, Hvas AM, Nexø E: Assessment of vitamin $B(12)$ absorption based on the accumulation of orally administered cyanocobalamin on transcobalamin. Clin Chem 2010, 56:432-436.

doi:10.1186/1750-1172-7-56

Cite this article as: Tanner et al: Inherited cobalamin malabsorption.

Mutations in three genes reveal functional and ethnic patterns.

Orphanet Journal of Rare Diseases 2012 7:56.

\section{Submit your next manuscript to BioMed Central and take full advantage of:}

- Convenient online submission

- Thorough peer review

- No space constraints or color figure charges

- Immediate publication on acceptance

- Inclusion in PubMed, CAS, Scopus and Google Scholar

- Research which is freely available for redistribution 